\title{
POSMODERNISME LINDA HUTCHEON Poetics of Postmodernism (1989) dan Politics of Postmodernism (2002)
}

\author{
Supriyadi \\ Universitas Gadjah Mada \\ supriyad_ugm54@yahoo.com
}

\section{Pengantar}

Dalam buku Bertens The Idea of Postmodernism (1996: 20) disampaikan bahwa istilah "posmodern" telah digunakan sejak abad ke-19 (1870-an), dan muncul sebagai sebuah judul buku pada tahun 1926; istilah ini muncul lagi pada tahun 1934, tahun 1939, dan tahun 1940-an, dan sejak itu istilah posmodern banyak digunakan. Namun, istilah posmodern baru diperdebatkan pada tahun 1960an dalam berbagai bidang seni, dan satu-satunya bidang yang memiliki kontinuitas penggunaan pandangan posmodern adalah bidang sastra, paling tidak mulai dari tahun 1950-an sampai sekarang.

Pada tahun 1950-an, Charles Olson telah mengidentifikasi adanya arus antimodernis dan antirasionalis dalam puisi-puisi para penyair yang tergabung dalam Black Mountain. Selain itu, ia berulang-ulang menggunakan istilah "postmodern" dalam tulisan-tulisan dan kuliah-kuliahnya. Menurut Olson, budaya Barat dengan sengaja menutup dirinya terhadap pengalaman nyata keotentikan kehidupan karena orientasinya hanya pada rasionalisme (sebuah konsep yang digunakan sejak zaman Yunani). Olson berusaha mengembangkan pandangan poetika Heidegger yang memutuskan hubungan dengan tradisi rasionalis Barat yang angkuh (karena membuat realitas tunduk pada rasio) sehingga perlu dibangun kembali humanisme yang lebih otentik daripada humanisme subjektivis itu. Oleh William Spanos, pandangan Olson ini dianggap sebagai pelopor posmodernisme eksistensialis karena dipengaruhi oleh eksistensialisme Heidegger ("realitas" berbicara untuk dirinya sendiri, dan penyair hanya sebagai mediator). Pada tahun 1970-an, posmodernisme eksistensialis ini terdesak oleh gabungan posstrukturalisme dan Marxisme (Bertens, 1996: 21-22).

Ada banyak pendapat yang berbeda tentang pendefinisian posmodernisme, tetapi setidaknya pendapat-pendapat itu dapat dibedakan menjadi tiga kelompok. Yang pertama adalah kelompok yang menganggap bahwa posmodernisme merupakan kelanjutan dari modernisme sehingga kelompok ini dapat dikatakan meradikalisasi modernisme. Yang kedua adalah kelompok yang melawan posmodernisme. Termasuk kelompok kedua ini ialah posmodernisme Fredric Jameson yang tercermin dalam tulisannya "The Political Unconscious: Narrative as a Socially Symbolic Act" (1981) dan dalam "Postmodernism and Consumer Society" (dalam Foster, 1983: 111-125). Yang ketiga adalah kelompok yang menerima sekaligus menolak kehadiran modernisme. Posmodernisme Linda Hutcheon dan McHale termasuk kelompok yang ketiga ini.

Linda Hutcheon (1989: ix) mengakui bahwa gagasan posmodernismenya dalam fiksi banyak dipengaruhi oleh gagasan posmodern dalam arsitektur yang dirumuskan oleh Paolo Portogeshi dan Carles Jencks, dan yang diaktualisasikan oleh Ricardo Bofill, Aldo Rossi, Robert Stern, Charles Moore, dan lain-lain. Karya-karya sastra yang mirip dengan arsitektur postmodern antara lain Shame karya Salman Rusdhie, Loon Lake karya Doctorow, The Woman Warrior karya Kingston, dan lain-lain. Selain dalam arsitektur dan fiksi, karya-karya posmodern juga didapati dalam bentuk film, video, fotografi, lukisan, tarian, musik, dan lain-lain. Dalam hal musik posmodern, Emmanuel Subangun dalam bukunya yang berjudul Synga Derrida: Jejak langkah Posmodernisme di Indonesia (1995: 9-12) memberikan contoh musik dhang-dut sebagai musik posmodern karena musik ini merupakan gabungan dari musik "ngak-ngik-ngok" dengan musik India, Arab, dan Melayu ("namanya mungkin 'posmo dhang-dut"); musik ini dapat menjadi musik metal dan dapat pula romantis; alatnya terdiri dari seruling, gitar listrik, dan gendang; penyanyi dapat menyanyikan lagu sedih, tetapi dengan penuh senyuman dan goyang pinggul. 


\section{Poetika dan Politik Posmodernisme Hutcheon}

Hutcheon banyak menulis tentang posmodernisme. Buku-bukunya antara lain Narcissistic Narrative: The Metafictional Paradox (1980), A Theory of Parody: The Teachings of Twentieth-Century Art Forms (1985), A Poetics of Postmodernism: History, Theory, Fiction (1989), The Canadian Postmodern: A Study of Contemporary English-Canadian Fiction (1988), dan The Politics of Postmodernism (2002). Meskipun jarak waktu penulisan buku itu cukup jauh, dalam keempat bukunya itu pandangan Hutcheon tidak berubah, bahkan tulisan-tulisan yang kemudian cenderung memperkuat dan memperluas tulisantulisan sebelumnya. Dalam buku pertamanya, Narcissistic Narrative, Hutcheon tertarik pada "paradoks metafiksional" narasi-narasi sadar-diri yang menuntut keterpisahan dan sekaligus keterlibatan pembaca, sedangkan dalam buku yang kedua, A Theory of Parody, ketertarikannya meluas pada paradoks parodi sebagai penandaan perbedaan ironis pada jantung kesamaan dan sebagai pelanggaran konvensi. Berdasarkan definisi ini, parodi dihadirkan untuk diteliti dengan cara ganda yang menggabungkan semiotika dengan interteks formal (via Hutcheon, 1989: x).

Pada tulisan ini, secara khusus dibicarakan poetika dan politik posmodernisme yang terdapat dalam buku Hutcheon Poetics of Postmodernism (1989) dan Politics of Postmodernism (2002). Poetika posmodernisme Linda Hutcheon berusaha menjembatani poetika modernisme yang berfokus pada keotonoman dann keobjektifan karya sastra dengan poetika sosiologis yang berfokus pada aspek sosial, historis, dan politis karya sastra:

"... my focus here is on those points of significant overlap of theory with aesthetic practice which might guide us to articulate what I want to call a "poetics" of postmodernism, a flexible conceptual structure which could at once constitute and contain postmodern culture and our discourses both about it and adjacent to it. The points of overlap that seem most evident to me are those of the paradoxes set up when modernist aesthetic autonomy and self-reflexivity come up against a counterforce in the form of a grounding in the historical, social, and political world" (Hutcheon, 1989: ix).

Dalam hal ini, poetika posmodernisme Hutcheon mencoba melihat karya sastra dari dua sisi sekaligus, yaitu struktur dan isinya, serta sekaligus aspek konteksnya (aspek sosial, sejarah, dan politiknya). Sementara itu, politik posmodernisme Hutcheon menegaskan bahwa seni posmodern mau tidak mau harus bersifat politis meskipun sulit untuk bergerak lebih konkret yang berupa tindak politik (political act). Dalam hal ini, politik posmodernisme lebih bekerja dalam bidang ideologis, yaitu dengan cara mendenaturalisasi tatanan yang diterima begitu saja karena dianggap benar. Dengan mengadaptasi istilah Barthes tentang "doxa" (opini publik dan konsensus), posmodernisme Hutcheon bekerja untuk "mendedoksifikasi". Secara politis atau ideologis, posmodernisme Hutcheon mempertanyakan sesuatu (kekuatan) yang dianggap mapan, tidak terbantahkan, alami, berada di pusat, dan lain-lainnya sehingga menjadi kekuatan yang goyah, terbantahkan, kultural, berada di pinggiran, dan lain-lainnya. Sistem patriarkal, misalnya, telah lama menjadi kekuatan yang sangat mapan dan tidak terbantahkan karena antara lain didukung oleh hukum-hukum dalam agama, tradisi, dan negara. Namun, muncul pandangan dan gerakan feminisme yang mempertanyakan sistem patriarkal itu sehingga kemudian muncul wacana-wacana feminis yang membuktikan sistem patriarkal tidak mapan, terbantahkan, tidak alami (natural) tetapi kultural, terpinggirkan, dan lain-lain.

\section{Pendekatan Posmodernisme Hutcheon pada Karya Sastra}

Jika pada bagian sebelumnya disajikan gambaran umum mengenai poetika dan politik posmodernisme Linda Hutcheon, pada bagian ini disajikan pendekatannya pada karya sastra. Hutcheon memanfaatkan teori komunikasi Roman Jakobson untuk mengeksplisitkan gagasan posmodernismenya. Dengan kata lain, Hutcheon mencoba menggabungkan poetika dan politik posmodernisme dengan teori komunikasi Jakobson untuk mengkaji karya sastra. Dalam memanfaatkan 
teori Jakobson, secara khusus Hutcheon membahasnya pada Bab 5 "Contextualizing The Postmodern: Enunciation and The Revenge of 'Parole" dalam bukunya Poetics of Postmodernisme (1989: 74-86). Teori komunikasi Jakobson adalah sebagai berikut (dalam Hawkes: 1978: 83).

context

message

\begin{tabular}{|c|c|}
\hline (pemberi pesan) & $\begin{array}{l}\text { contact } \\
\text { code }\end{array}$ \\
\hline
\end{tabular}

Dapat disimpulkan bahwa pendekatan posmodernisme Hutcheon pada karya sastra adalah sebagai berikut.

(1) Struktur karya sastra bersifat "parodis yang posmodern". Yang dimaksud dengan "parodi posmodern" ialah penggunaan dan penyimpangan teks-teks sebelumnya untuk membangun sebuah karya sastra. Dengan kata lain, karya sastra terbentuk atas banyak teks sebelumnya yang sengaja digunakan dan disimpangi (used and misused) untuk menyampaikan gagasan pengarangnya, bukan untuk menceritakan kembali nostalgia atau peristiwa masa lalu.

(2) Struktur karya sastra dibangun dalam bentuk pusat dan pinggiran. Dalam bentuk seperti ini, posmodernisme Hutcheon berusaha mengangkat pinggiran dan menggoyahkan pusat:

"the point is that postmodernism has been both acclaimed and attacked by both ends of the political spectrum because its inherently paradoxical structure permits contradictory interpretations: these forms of aesthetic practice and theory both install and subvert prevailing norms — artistic and ideological. They are both critical and complicitous, outside and inside the dominant discourses of society" (Hutcheon, 1989: 222).

Posmodernisme Hutcheon tidak menganggap bahwa pusat harus didestruksi (dihancurkan), tetapi cukup didekonstruksi (dipertanyakan dan dipersaingkan) agar kedominanannya menjadi tidak mutlak sehingga kehadiran pinggiran diakui.

(3) Karya sastra posmodern perlu dikontekstualisasikan dengan lingkungan penciptaannya (aspek sosial, historis, dan politisnya). Hal ini disebabkan karya sastra posmodern tidak bersifat nostalgis (untuk menceritakan kembali peristiwa masa lalu), tetapi bersifat kritis dan (untuk mengkritisi kondisi masyarakat ketika karya itu diciptakan).

"what I want to callpostmodernism is fundamentally contradictory, resolutely historical, and inescapably political. Its contradictions may well be those of late capitalist society, but whatever the cause, these contradictions are certainly manifest in the important postmodern concept of "the presence of the past" (Hutcheon, 1989: 4).

(4) Sebagai bagian dari komunikasi, kehadiran pengarang (addresser, speaker) dan pembaca (addressee, listener) dipertimbangkan dalam pendekatan posmodern. Dalam hal ini, pengarang yang dimaksudkan adalah pengarang yang ada (implisit) di dalam karya sastra dan pengarang sebagai bagian dari masyarakat ketika karya itu diciptakan. Kehadiran pengarang di dalam karya sastranya dapat ditandai melalui suara-suara kepengarangannya (authorial voices), pusat pengisahan (point of view), narator, dan tokoh-tokoh tertentu.

"Nevertheless, the lesson of postmodern art is that we must not limit our investigations to just readers and texts; the process of production too cannot be ignored. In discussing freedom and constraint in the reading process, Jonathan Culler has asserted that there "must always be dualisms: an interpreter and something to interpret" (1982b, 75; see too Josipovici 1982, 33). But postmodernism suggests that there is more to it than this. The 
enunciation requires more than just text and receiver in order to activate the dynamic process of meaninggenerating" (Metscher 1972 and 1975). (Hutcheon, 1989: 80).

Meskipun demikian, peran pembaca sangat penting karena melalui proses pembacaan, makna karya sastra itu dihasilkan.

\section{Contoh Analisis}

Selanjutnya disajikan contoh analisis posmodernisme Linda Hutcheon dalam salah satu novel Indonesia, yaitu Arok Dedes (1998) karya Pramoedya Ananta Toer. Novel ini menarik untuk dikaji secara posmodern karena menggunakan teks-teks sejarah yang menggambarkan peralihan kekuasaan di Tumapel, dari Tunggul Ametung ke Ken Arok. Dalam novelnya ini, Pramoedya tidak mencoba secara nostalgis menceritakan kembali peristiwa keruntuhan kekuasaan Tunggul Ametung secara apa adanya, tetapi menggunakannya untuk mempertanyakan kondisi sosial masyarakatnya, yakni mempertanyakan peristiwa peralihan kekuasaan dari Orde Lama (Presiden Soekarno) ke Orde Baru (Presiden Soeharto).

\section{Penggunaan dan Penyimpangan Teks Sejarah dalam Arok Dedes}

Penciptaan karya sastra dalam wujud novel sejarah berbeda dengan penulisan sejarah. Jika dalam penulisan sejarah, penulis berusaha menyampaikan fakta sejarah seobjektif mungkin, dalam penciptaan novel sejarah, pengarang cenderung menambahkan imajinasinya sesuai dengan kehendak dan gagasannya, bahkan pengarang sengaja menyimpangi fakta sejarah demi mendukung gagasannya. Salah satu novel sejarah yang banyak menyimpangi fakta sejarah adalah Arok Dedes karya Pramoedya Ananta Toer. Novel ini tampaknya banyak mengacu pada cerita sejarah yang berasal dari kita Pararaton, tetapi tidak sepenuhnya diacu karena ternyata banyak didapati penyimpangan, terutama berhubungan dengan watak dan sikap tokoh, alur, dan latar. Hampir semua tokoh dalam novel itu diceritakan secara berbeda dari segi watak dan pandangannya jika dibandingkan dengan apa yang ada dalam Pararaton meskipun jalan ceritanya hampir sama, yaitu tentang peralihan kekuasaan dari Tunggul Ametung ke Arok karena kudeta.

Penyimpangan pertama yaitu penyimpangan mengenai penggambaran tokoh Arok. Penyimpangan ini meliputi penceritaan asal usul Arok, penggambaran kekuatan supranatural yang dimilikinya, dan penggambaran kecerdasaannya. Dalam Serat Pararaton (1979: 15- 21), diceritakan bahwa Arok adalah anak Dewa Brahma, sedangkan di dalam novel diceritakan bahwa Arok anak orang biasa. Tampaknya ada penekanan yang berbeda di antara keduanya. Serat Pararaton cenderung melegitimasi atau mengukuhkan Arok sebagai penguasa yang sah di Tumapel (dan juga di Singasari), sedangkan novel Arok Dedes cenderung memandang sinis keberhasilan Arok dalam menyingkirkan penguasa sah Tumapel. Dapat dikatakan, terjadi desakralisasi atau delegitimasi tokoh Arok dalam novel itu. Dengan demikian, dalam novel itu, digambarkan Arok adalah seorang calon penguasa yang berjuang dari bawah (seorang sudra) yang melalui pendidikan (brahmana) dapat menjadi punggawa Tumapel (ksatria), bahkan kemudian berhasil menjadi akuwu, dan akhirnya menjadi raja meskipun harus melewati intrik-intrik yang melelahkan. Ia menjadi akuwu bukan karena ia keturunan dewa, tetapi karena kegigihan dan keuletan perjuangannya, bahkan dengan kelicikannya. Ia pandai mengatur siasat dan melobi sekaligus menjebak banyak tokoh sehingga mereka masuk perangkap rencananya. Arok adalah tokoh yang berhasil membangun intrik-intrik di Tumapel untuk kemudian memanfaatkan untuk kepentingannya sendiri, yaitu menjadi penguasa di Tumapel, dan kemudian ia berhasil menjadi penguasa sebuah kerajaan yang besar, Singasari. Pada bagian akhir novel, ditegaskan kembali dengan nada sinis bahwa kemenangannya itu berkat "muslibat bermuka ganda dan cara tanpa bilangan" (2002: 413).

Seperti dalam pembahasan penyimpangan yang berhubungan dengan penggambaran tokoh Arok, penyimpangan dalam penggambaran tokoh Dedes ini cenderung membandingkan apa yang 
ada dalam Serat Pararaton dengan novel Arok Dedes. Dalam hal ini, terdapat penyimpangan yang cukup tajam karena dalam novel diceritakan bahwa Dedes adalah seorang perempuan yang cerdas, tidak mau menyerah pada nasib, dan haus kekuasaan. Hal ini berbeda dengan gambaran sebelumnya yang cenderung menceritakan Dedes sebagai seoran wanita yang sangat cantik sehingga setiap lelaki jatuh cinta kepadanya.

Fungsi penggunaan dan penyimpangan fakta sejarah:

i. $\quad$ untuk mengalegorikan tokoh-tokoh politik yang berkuasa;

ii. untuk menyembunyikan gagasan utama novel;

iii. untuk menghasilkan nilai estetis tertentu (defamiliarisasi).

\section{Pusat dan Pinggiran dalam Arok Dedes}

Pada dasarnya, novel itu mempertanyakan wacana dominan tentang peristiwa peralihan kekuasaan dari Orde Lama ke Orde Baru. Wacana dominan yang dimaksud ialah bahwa peralihan kekuasaan itu terjadi karena militer berhasil menumpas Pemberontakan G30S/PKI. Sementara itu, novel Arok Dedes berusaha mempertanyakannya dengan cara menyajikan cerita sebaliknya, yakni militer (Soeharto) mengkudeta pemerintahan Orde Lama (Soekarno). Pemertanyaan ini dibangun melalui hubungan pusat dan pinggiran dalam beragama, pusat dan pinggiran dalam perbedaan kasta, pusat dan pinggiran dalam perbedaan laki-laki dan perempuan, dan sebagainya.

\section{Kontekstualisasi Novel Arok Dedes}

Konteks novel Arok Dedes adalah kehidupan masyarakat Indonesia ketika pemerintahan Soeharto telah mengalami deotoriterisasi dan demiliterisasi. Dalam hal ini, rakyat mulai berani menyampaikan kritik-kritik yang tajam terhadap pemerintahan dan menghendaki perubahan nyata sistem pemerintahan yang ada, bahkan rakyat berhasil melengserkan Soeharto dengan Orde Baru, dan menggantikannya dengan Orde Reformasi. Dengan demikian, konteks-konteks novel Arok Dedes dapat dibedakan menjadi konteks demiliterisasi, deotoriterisasi, dan konteks keterbukaan.

\section{Penutup}

Pandangan posmodernisme Linda Hutcheon cukup menarik karena terkandung konsep kesetaraan, kebebasan, dan kemerdekaan. Dengan mempertanyakan sesuatu yang dianggap pusat (mutlak, dominan, menindas, berkuasa, dan lain-lainnya), pandangan ini mencoba mengangkat sesuatu yang dianggap pinggiran (relatif, tidak dominan, tertindas, dikuasai, dan lain-lain) menjadi setara dengan yang dianggap pusat.

\section{Daftar Pustaka}

Bertens, Hans. 1996. The Idea of the Postmodernism: A History. Cet. ke-3. Routledge, New York.

Hawkes, Terence. 1978. Structuralism and Semiotics. Cet. ke-2. Methuen, London.

Hutcheon, Linda. 1980. Narcissistic Narrative: The Metafictional Paradox. Wilfrid Laurier

University Press., Waterloo - Ontario.

.1985. A Theory of Parody: The Teachings of Twentieth-Century Art Forms.

Methuen, London dan New York.

-. 1989. A Poetics of Postmodernism: History, Theory, Fiction. Cet. ke-1. Routledge.

New York dan London.

----------. 2004. Politik Posmodernisme Linda Hutcheon. Diterjemahkan oleh Apri Danarto.

Cet. ke-1. Penerbit Jendela, Yogyakarta.

Toer, Pramoedya Ananta. 2002. Arok Dedes. Cet. ke-5. Hasta Mitra, Yogyakarta. 